\title{
OPTIMALISASI MEDIA FILTER PADA INSTALASI PENGOLAHAN AIR BERSIH DI PONDOK PESANTREN AL IZZAH KM 15 BALIKPAPAN
}

\author{
Marita Wulandari ${ }^{1)}$, Rahmania $^{2)}$, Nia Febrianti ${ }^{3)}$ \\ 1)Program Studi Teknik Lingkungan, Institut Teknologi Kalimantan, Balikpapan, Kalimantan Timur, Indonesia \\ 2) Program Studi Fisika, Institut Teknologi Kalimantan, Balikpapan, Kalimantan Timur, Indonesia \\ ${ }^{3)}$ Program Studi Teknik Lingkungan, Institut Teknologi Kalimantan, Balikpapan, Kalimantan Timur, Indonesia \\ Corresponding author : Marita Wulandari \\ E-mail : maritawulandari@lecturer.itk.ac.id
}

\section{Diterima 05 November 2020, Direvisi 18 November 2020, Disetujui 18 November 2020}

\begin{abstract}
ABSTRAK
Salah satu unsur utama dalam kehidupan adalah air. Balikpapan memiliki sumber air baku yang berasal dari waduk untuk memenuhi kebutuhan air bersih warga Kota Balikpapan. Namun masih banyak warga yang menggunakan air sumur. Air sumur yang digunakan masyarakat masih berwarna coklat dan agak kekuning-kuningan yang diakibatkan konsentrasi besi dan mangan yang tinggi. Salah satu yang masih menggunakan air sumur bor ini ialah tempat penyedia pendidikan yaitu di Pondok Pesantren Al- Izzah yang terletak di Jalan Sei Wein KM 15 Kelurahan Karang Joang Kecamatan Balikpapan Utara. Salah satu bentuk pengabdian masyarakat ini adalah melakukan optimalisasi instalasi pengolahan air bersih yang terdapat di Pondok Pesantren Al- Izzah, agar proses pengolahan air bersih menjadi optimal dan air bersih yang dihasilkan dapat sesuai standar dengan cara mengganti media filter yang ada pada bak filtrasi dengan menggunakan media filter karbon aktif, pasir silika, ijuk, dan kerikil. Berikut prodesur kerja pembuatan instalasi pengolahan air bersih, survei dan peninjauan untuk menentukan media filter berdasarkan karakteristik air baku, persiapan media filter, pembersihan bak filtrasi, pengisian media filter, dan tahapan yang terakhir ialah pengujian kualitas air sebelum dan sesudah media filter diganti. Hasil yang didapat setelah media filter di ganti dan dioptimalkan ialah bahwa efisiensi penyisihan kekeruhan sebesar $99,86 \%$. Efisiensi penyisihan TDS sebesar $55,83 \%$. Penurunan konsentrasi besi dan mangan masing masing sebesar $99,37 \%$ dan $87,44 \%$.
\end{abstract}

Kata kunci: air bersih; media filter; besi dan mangan; kekeruhan

\begin{abstract}
One of the important thing in human life is water. To provide the the need of water in Balikpapan, Balikpapan has a sorce of raw water was come from reservoar. However, many residents still use well water. The well water used by the community is still brown and slightly yellowish due to the high concentration of iron and manganese. Al-Izzah Islamic Boarding School which is located on Jalan Sei Wein KM 15, Karang Joang Village, North Balikpapan District has a problem with water. The student, teacher, and some people in there used well water. This community service was optimizing the clean water treatment installation at the Al-Izzah Islamic Boarding School, so that the clean water treatment process can be optimal and the clean water produced can be up to standard by replacing the existing filter media in the filtration tub using media activated carbon filter, silica sand, palm fiber, and gravel. The following was a work process for making a clean water treatment plant, a survey and a review to determine the filter media based on the characteristics of raw water, preparation of filter media, cleaning the filtration tub, filling the filter media, and the last step is testing the water quality before and after the filter media is replaced. The results obtained after the filter media were replaced and optimized was that the turbidity removal efficiency was $99.86 \%$. TDS removal efficiency of $55.83 \%$. The decrease in iron and manganese concentrations was $99.37 \%$ and $87.44 \%$, respectively.
\end{abstract}

Keywords: clean water; filter media; iron and manganese; turbidity

\section{PENDAHULUAN}

Salah satu unsur utama dalam kehidupan adalah air. Balikpapan memiliki sumber air baku yang berasal dari waduk untuk memenuhi kebutuhan air bersih warga Kota Balikpapan. Ketersediaan air bersih sangat penting untuk menunjang kehidupan. Akan tetapi tidak semua tempat tinggal masyarakat terjangkau dan memiliki sumber air bersih dari PDAM. Beberapa warga yang tidak memiliki jaringan air bersih yang berasal dari PDAM akan menggunakan air sumur dan air hujan 
untuk memenuhi kebutuhan sehari-harinya seperti mandi, mencuci, masak dan lain sebagainya. Air sumur yang digunakan masyarakat masih berwarna coklat dan agak kekuning-kuningan. Salah satu tempat penyedia pendidikan yaitu di Pondok Pesantren Al- Izzah yang terletak di Jalan Sei Wein KM 15 Kelurahan Karang Joang Kecamatan Balikpapan Utara. Pondok pesantren selain berfungsi sebagai lembaga pendidikan Islam, juga berperan sangat penting dalam pembangunan dan perubahan di masyarakat. Untuk menunjang suasana pembelajaran dan kegiatan yang nyaman, faktor kualitas air menjadi hal yang penting. Pemenuhan kebutuhan air bersih menjadi hal yang mutlak di Pondok Pesantren Al Izzah.

Pondok pesantren ini memiliki sumur yang dijadikan sebagai sumber air bersih untuk memenuhi kebutuhan sehari-hari para guru dan santri-santrinya. Sebelum digunakan air sumur yang terdapat di Pondok Pesantren Al- Izzah terlebih dahulu diolah menggunakan filter yang berbasis sistem saringan pasir lambat. (Riduan et al., 2019). Sistem penyaring air sederhana adalah sistem yang pal ing banyak digunakan baik itu kegunaan rumah tangga hingga kegunaan Industri. Media saringan berfungsi sebagai penyaring yang terdiri dari media filtrasi dan media penyangga. (Wicaksono et al., 2019). Pengolahan sederhana yang digunakan oleh Pondok Pesantren Al- Izzah dapat mengurangi warna dan kadar kekeruhan dari air sumur tersebut. Akan tetapi proses pengolahan air sumur di Pesantren Al- Izzah terkadang kurang efektif misalnya proses yang lama untuk menghasilkan air bersih, serta air yang masih keruh dan berbau, dan beriminyak.

Menurut (Trigunarso et al., 2019) air yang berubah warna menjadi kuning-coklat setelah beberapa saat kontak dengan udara disebabkan oleh kandungan kadar B esi (Fe) dan Mangan $(\mathrm{Mn})$ yang tinggi. Air masih mengandung besi dan mangan yag tinggi walaupun telah ada unit filtrasi dapat disebabkan oleh beberapa faktor seperti media filter yang belum sesuai atau kurang optimal, serta media filter yang terdapat dalam instalasi pengolahan air bersih tersebut tidak diganti secara berkala sehingga filtrasi belum bekerja secara optimal.

Media filter harus diganti agar menghasilkan air bersih yang memenuhi syarat sesuai dengan baku mutu yang ada pada (Menteri Kesehatan Republik Indonesia, 2017) tentang Standar Baku Mutu Kesehatan Lingkungan untuk Keperluan Higiene Sanitasi. Unit pengolahan ini perlu perawatan dalam implementasinya. Perawatan secara sederhana dapat dilakukan secara berkala seperti sebulan sekali untuk membersihkan sedimen dan lumut yang ada pada alat, setelah beroperasi. Perawatan ini contohnya pengerukan lapisan dan pencucian pasir serta pencucian bahan bahan filter lainnya. Gambar 1 merupakan bak filtrasi pada lokasi mitra yang selama ini digunakan sebagai bak pengolahan air sumur.

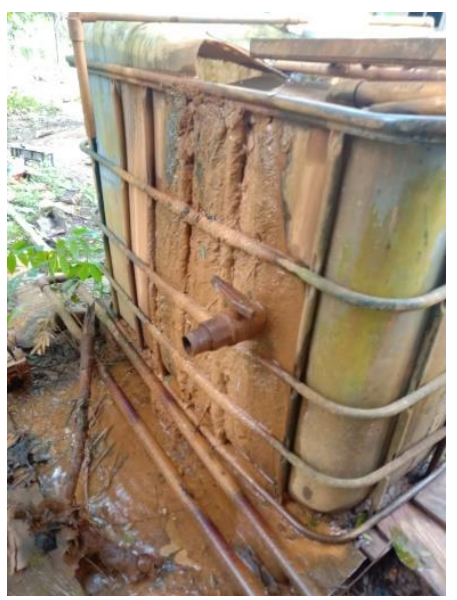

Gambar 1. Kondisi Eksisting Bak Filtrasi di Lokasi Mitra

Maka dari itu salah satu bentuk pengabdian masyarakat ini adalah melakukan optimalisasi instalasi pengolahan air bersih yang terdapat di Pondok Pesantren Al- Izzah, agar proses pengolahan air bersih menjadi optimal dan air bersih yang dihasilkan dapat sesuai standar dengan cara mengganti media filter yang ada pada bak filtrasi.

Manfaat kegiatan yang diharapkan melalui kegiatan pelatihan dan perbaikan media filter air ini ialah adalah meningkatkan pengetahuan dan keterampilan masyarakat/penghuni pesantren dalam perawatan teknologi pengolahan air bersih (filtrasi) dan dari sisi ekonomi ialah dengan adanya optimalisasi alat filtrasi ini, maka pihak pesantren tidak perlu membeli air bersih, sehingga dapat mengurangi pengeluaran pesantren.

\section{METODE \\ Waktu dan Lokasi}

Pengabdian masyarakat ini dilaksanakan pada hari Minggu, 12 Juli2020. Pesantren ini terletak di JL. Sei Wain, RT.33 No.02, Balikpapan Utara, Telaga Sari, Balikpapan, Kota Balikpapan, Kalimantan Timur 76112, Indonesia. Pesantren ini berjarak 2,6 km dari Kampus Institut Teknologi Kalimantan. Pondok Pesantren Al-Izzah Balikpapan, dikenal pula sebagai "Pesantren Mahasiswa" karena tidak sedikit mahasiswa yang masuk dalam pesantren tersebut, apalagi dekat dengan Institut Teknologi Kalimantan (ITK). 


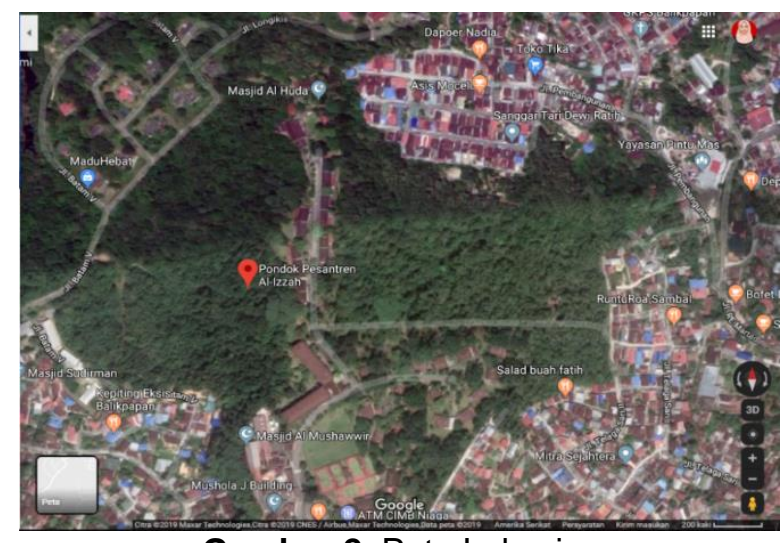

Gambar 2. Peta Lokasi

\section{Alat dan Bahan}

Peralatan dan bahan yang digunakan dalam optimalisasi instalasi pengolahan air bersih dapat dilihat pada Tabel 1

Tabel 1. Alat dan Bahan yang Digunakan

\begin{tabular}{|c|c|c|c|}
\hline No & $\begin{array}{l}\text { Alat dan } \\
\text { Bahan }\end{array}$ & No & Alat dan Bahan \\
\hline 1 & Karbon Aktif & 6 & $\mathrm{pH}$ meter \\
\hline 2 & Pasir Silika & 7 & $\begin{array}{l}\text { Konduktivitas } \\
\text { Listrik }\end{array}$ \\
\hline 3 & ljuk & 8 & TDS meter \\
\hline 4 & Kerikil & 9 & Termometer \\
\hline 5 & Kassa filter & 10 & DO meter \\
\hline
\end{tabular}

\section{Prosedur Kerja}

Secara umum, ada dua jenis prosedur kerja yang dikerjakan dalam pengabdian masyarakat ini. Pertama ialah regenerasi media filter pada bak filtrasi, dan yang kedua ialah pengujian kualitas air sumur (sebelum dan sesudah penggantian media filter).

\section{Peninjauan Lokasi dan Sosialisasi}

Sosialisasi tahap awal akan dilakukan kepada tokoh masyarakat yaitu ketua RT dan pengurus pesantren, dan masyarakat di sekitar pesantren. Permohonan ijin akan dilakukan kepada pihak Kelurahan Karang Joang dan koordinasi akan dilakukan lebih lanjut seiring dengan berjalannya program dengan mitra kegiatan ini.

\section{Regenerasi dan Optimalisasi Media Filter Instalasi Pengolahan Air Bersih}

Berikut prodesur kerja pembuatan instalasi pengolahan air bersih :

1. Tahap 1 : Survei dan peninjauan untuk menentukan media filter berdasarkan karakteristik air baku

2. Tahap 2 : Persiapan media filter yaitu kerikil diameter 5-10 mm, karbon aktif, pasir silica, ijuk, dan kassa dilakukan pencucian hingga bersih dengan menggunakan air mengalir kemudian dijemur di bawah sinar matahri sampai kering.

3. Tahap 3 : Pembersihan bak filtrasi. Tahap ini bertujuan untuk membersihkan bak filtrasi yang menguning-kecoklatan akibat oksidasi air dengan udara.

4. Tahap 4 : Pengisian media filter dibantu dengan warga dan santri yang ada di lokasi mitra (Pesantren Al Izzah)

\section{Pengujian Kualitas Air}

Uji kualitas air ini dilakukan pada air baku (air sumur bor). Adapun parameter yang diuji untuk menentukan kualitas air bersih ini ditunjukkan pada Tabel 2.

Tabel 2. Parameter dan Metode Pengukuran Kualitas Air

\begin{tabular}{|c|c|c|}
\hline No & Parameter & $\begin{array}{l}\text { Metode } \\
\text { Pengukuran }\end{array}$ \\
\hline 1 & $\mathrm{pH}$ & $\mathrm{pH}$ meter \\
\hline 2 & TDS & TDS meter \\
\hline 3 & $\begin{array}{l}\text { Dissolved } \\
\text { Oxygen (DO) }\end{array}$ & DO meter \\
\hline 4 & Suhu & Termometer \\
\hline 5 & $\begin{array}{l}\text { Konduktivitas } \\
\text { Listrik }\end{array}$ & Conductivity meter \\
\hline 6 & Kekeruhan & Turbidity meter \\
\hline 7 & Rasa & Organoleptik \\
\hline 8 & Besi & $\begin{array}{l}\text { Spektofotometer } \\
\text { Serapan Atom }\end{array}$ \\
\hline 9 & Mangan & $\begin{array}{l}\text { Spektofotometer } \\
\text { Serapan Atom }\end{array}$ \\
\hline 10 & Fluorida & $\begin{array}{l}\text { Spektofotometer } \\
\text { Serapan Atom }\end{array}$ \\
\hline
\end{tabular}

\section{HASIL DAN PEMBAHASAN}

\section{Survey dan Peninjauan Lokasi}

Survei dan peninjauan lokasi ini dilakukan pada Tanggal 5 Juli 2020 atau satu minggu sebelum kegiatan pengabdian masyarakat dilakukan. Survey ini bertujuan untuk mengetahui alat dan bahan apa saja yang dibutuhkan di lapangan agar tepat sasaran. Koordinasi dengan mitra terkait juga dilakukan, untuk mengetahui permasalahan yang biasa terjadi pada unit pengolahan air bersih. Berdasarkan pengamatan, dapat dilihat bahwa pada bak filter terdapat kerak berwarna kuning. Air tanah sering mengandung zat besi $(\mathrm{Fe})$ dan Mangan (Mn) cukup besar. Adanya kandungan $\mathrm{Fe}$ dan $\mathrm{Mn}$ dalam air menyebabkan warna air tersebut berubah menjadi kuning-coklat setelah beberapa saat kontak dengan udara. Disamping dapat mengganggu kesehatan juga menimbulkan bau yang kurang enak serta menyebabkan warna kuning pada diding bak serta bercak-bercak kuning pada pakaian. 

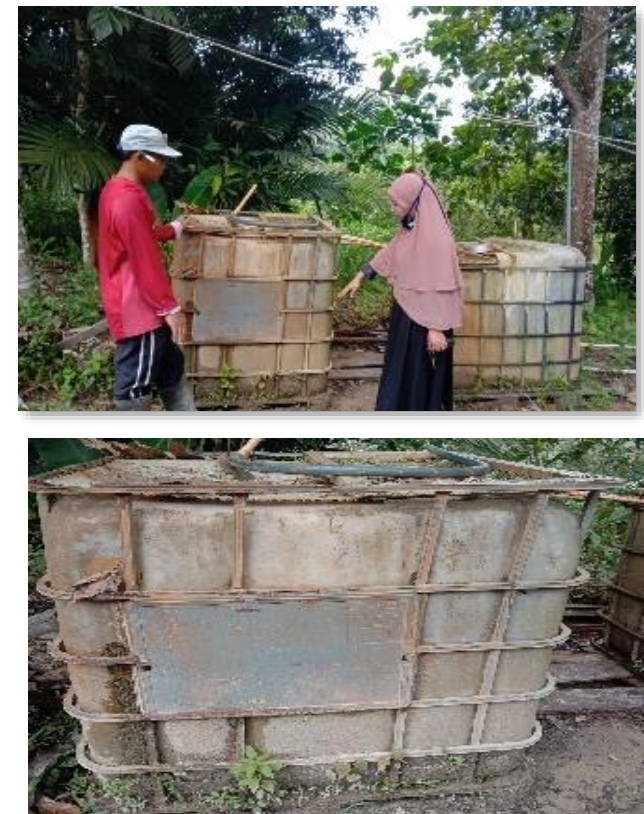

Gambar 3. Bak Yang Digunakan Untuk Proses Filtrasi Air Sumur Pada Lokasi Mitra

\section{Persiapan Media filter}

Media filter yang digunakan ialah kerikil, pasir, ijuk, dan karbon aktif. Karbon aktif merupakan senyawa amorf yang dihasilkan dari bahan-bahan yang mengandung karbon atau arang yang diperlakukan secara khusus untuk mendapatkan daya adsorpsi yang tinggi. Karbon aktif sebagai media filter yang digunakan untuk pemurnian air, menghilangkan bau, rasa dan salah satu bahan alternatif yang digunakan untuk mengurangi kadar logam besi dan mangan pada air (Nunik \& DG Okayadnya, 2013).

\section{Pengisian Media Filter}

Media filter diisikan pada bak yang memiliki volume $1 \mathrm{~m}^{3}$. Media filter yang digunakan ialah kerikil, pasir, ijuk, dan karbon aktif. Untuk pengisian media filter, susunannya ialah lapisan paling bawah yakni kerikil. Diatas lapisan kerikil yakni pasir silika, kemudian karbon aktif, ijuk, dan lapisan paling atas ialah pasir biasa. Masing-masing lapisan diberi tambahan kain kassa agar media filter yang berbeda tidak bercampur. Proses pengisian media filter kedalam bak filtrasi dapat dilihat pada Gambar 4.

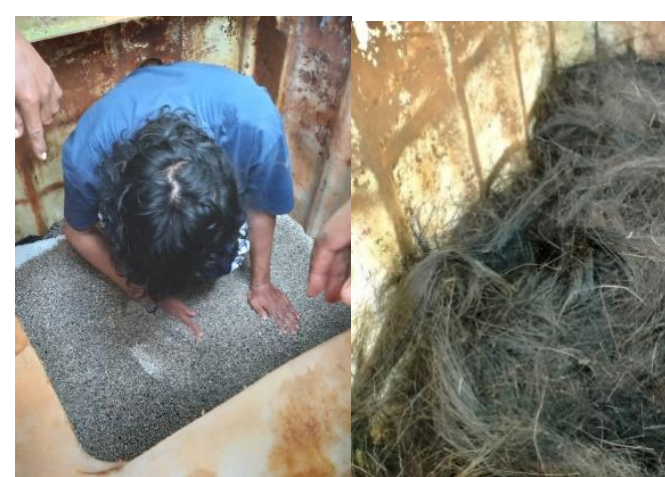

Gambar 4. Pengisian Media Filter (Pasir Silika, ljuk, Karbon Aktif)

\section{Pengujian Kualitas Air}

Setelah semua media filter dibersihkan dan diisikan pada bak filtrasi, maka selanjutnya ialah menguji kualitas air bersih, untuk melihat seberapa efektif alat filter tersebut. Adapun hasilnya dapat dilihat pada Tabel 3 :

Tabel 3. Kualitas Air Sebelum dan Sesudah Penggantian dan Regenerasi Media Filter

\begin{tabular}{|c|c|c|c|c|}
\hline Parameter & Satuan & Sebelum & Sesudah & $\begin{array}{c}\text { Kadar } \\
\text { Maksimum } \\
\text { Diperbolehkan }\end{array}$ \\
\hline Suhu & ${ }^{\circ} \mathrm{C}$ & 26,5 & 27 & $\begin{array}{c}\text { Suhu udara } \pm \\
3\end{array}$ \\
\hline TDS & $\mathrm{mg} / \mathrm{L}$ & 120 & 53 & 1000 \\
\hline $\begin{array}{l}\text { Konduktivitas } \\
\text { Listrik }\end{array}$ & $\mu \mathrm{S} / \mathrm{cm}$ & 180,2 & 172 & - \\
\hline Kekeruhan & NTU & 212 & 0,29 & 25 \\
\hline Rasa & - & $\begin{array}{l}\text { Tidak } \\
\text { Berasa }\end{array}$ & $\begin{array}{l}\text { Tidak } \\
\text { Berasa }\end{array}$ & Tidak Berasa \\
\hline $\mathrm{pH}$ & - & 6,4 & 6,2 & $6,5-8,5$ \\
\hline Besi & $\mathrm{mg} / \mathrm{L}$ & 8,02 & 0,05 & 1 \\
\hline Mangan & $\mathrm{mg} / \mathrm{L}$ & 2,15 & 0,27 & 0,5 \\
\hline Fluorida & $\mathrm{mg} / \mathrm{L}$ & $<0,10$ & $<0,10$ & 1,5 \\
\hline
\end{tabular}

Berdasarkan hasil pengujian kuantitatif dan dibandingkan dengan baku mutu PERMENKES RI : No. 32/MENKES/ 2017, tentang Standar Baku Mutu Kesehatan Lingkungan untuk Keperluan Higiene Sanitasi, diketahui bahwa beberapa parameter pada sampel air baku tidak sesuai dengan standar air bersih. Salah satu upaya untuk meningkatkan kualitas air sumur yang keruh dan berbau ialah dengan cara penyaringan dengan membuat saringan pasir lambat yang diisi dengan media filter kerikil, karbon aktif, ijuk dan pasir. Karbon aktif disini berperan sebagai adsorben untuk logam berat Besi dan Mangan.

Nilai kekeruhan sebesar 212 NTU, dimana batas maksimum yang diperbolehkan menurut peraturan sebesar 25 NTU. Penyebab kekeruhan pada air adalah adanya zat padat yang tersuspensi yaitu baik yang bersifat anorganik mauun organik. Zat organik biasanya berasal dari lapukan tumbuhan dan hewan, dimana zat organik ini biasanya dapat menjadi makanan bagi mikroorganisme sehingga pertambahan mikroorganisme dapat meningkatkan kekeruhan pada air. Sedangkan 
zat anorganik berasal dari lapukan batuan dan logam. Air yang memiliki tingkat kekeruhan yang tinggi akan lebih sulit untuk diolah menjadi air bersih, terutama pada proses penyaringan, selain itu kekeruhan juga akan membuat air akan sulit untuk didesinfeksi karena mikroba terlindungi oleh zat yang tersuspensi (Parera et al., 2013).

Setelah dilakukan penggantian dan optimalisasi media filter, didapatkan nilai kekeruhan akhir sebesar 0,29 NTU. Ini berarti bahwa efisiensi penyisihan kekeruhan sebesar 99,86 \%. Meskipun nilai TDS sampel air baku menunjukkan nilai yang berada dibawah baku mutu, namun penggantian media filter mampu menurunkan nilai TDS dengan efisiensi penyisihan sebesar 55,83 \%. Sementara konsentrasi besi dan mangan pada sampel air baku menunjukkan nilai diatas baku mutu, dan terjadi penurunan konsentrasi besi dan mangan masing masing sebesar 99,37 \% dan 87, $44 \%$ saat setelah penggantian media filter.

\section{SIMPULAN DAN SARAN}

Kegiatan pengabdian masyarakat di Pesantren Al Izzah, Kelurahan Karang Joang, Balikpapan telah berhasil dilaksanakan, dimana penggantian media filter ini mampu untuk meningkatkan kualitas air bersih. Nilai kekeruhan, besi, mangan awal yang sebelumnya diatas baku mutu, setelah dilakukan regenerasi dan optimalisasi dengan penambahan media filter, terjadi penurunan konsentrasi hingga pada nilai yang dapat ditolerir (dibawah baku mutu) menurut PERMENKES RI : No. 32/MENKES/ 2017, tentang Standar Baku Mutu Kesehatan Lingkungan untuk Keperluan Higiene Sanitasi

\section{UCAPAN TERIMAKASIH}

Penulis mengucapkan terima kasih kepada Lembaga Penelitian dan Pengabdian Masyarakat, Insitutu Teknologi Kalimantan yang telah memberikan bantuan finansial sehingga program kegiatan pengabdian masyarakat ini dapat berjalan dengan baik. Selain itu ucapan terima kasih juga kepada mitra yakni Pondok Pesantren Al Izzah, Km 15, Kelurahan Karang Joang, Balikpapan yang membantu dalam pelaksanaan kegiatan kemitraan ini.

\section{DAFTAR RUJUKAN}

Menteri Kesehatan Republik Indonesia. (2017). Peraturan Menteri Kesehatan Republik Indonesia Nomor 32 Tahun 2017 Tentang Standar Baku Mutu Kesehatan Lingkungan Dan Persyaratan Kesehatan Air Untuk Keperluan Higiene Sanitasi, Kolam Renang, Solus Per Aqua dan
Pemandian Umum. Peraturan Menteri Kesehatan Republik Indonesia, 1-20.

Nunik, P., \& DG Okayadnya, -. (2013). PENYISIHAN LOGAM BESI (Fe) PADA AIR SUMUR DENGAN KARBON AKTIF DARI TEMPURUNG KEMIRI. Envirotek: Jurnal IImiah Teknik Lingkungan, 5(2), 33-41.

Parera, M. J., Supit, W., \& Rumampuk, J. F. (2013). Analisis Perbedaan Pada Uji Kualitas Air Sumur Di Kelurahan Madidir Ure Kota Bitung Berdasarkan Parameter Fisika. Jurnal E-Biomedik, 1(1), 466-472. https://doi.org/10.35790/ebm.1.1.2013.45 84

Riduan, A., Rainiyati, R., Heraningsih, S. F., \& Ariansyah, D. (2019). Produksi Air Bersih di Ma'had Rizqullah Desa Simpang Sungai Duren Kecamatan Jambi Luar Kota Muara Jambi. Jurnal Pengabdian Pada Masyarakat, 4(4), 547-554. https://doi.org/10.30653/002.201944.225

Trigunarso, S. I., Mulyono, R. A., \& Suprawihadi, R. (2019). Alat Pengolah Air Tanah Menjadi Air Bersih dengan Proses Kombinasi Aerasi-Filtrasi Upflow (Desain Rancang Bangun). Jurnal Kesehatan, 10(1), 53. https://doi.org/10.26630/jk.v10i1.1174

Wicaksono, B., Mayasari, D., P, P. S., Iduwin, T., \& Yuhanah, T. (2019). Edukasi Alat Penjernih Air Sederhana Sebagai Upaya Pemenuhan Kebutuhan Air Bersih. Terang: Jurnal Pengabdian Pada Masyarakat Menerangi Negeri, 2(1), 4352. 